\title{
Determination of Phenolic Compounds in Red Sweet Pepper (Capsicum annuum L.) Using a Modified QuEChERS Method and UHPLC-MS/MS Analysis and Its Relation to Antioxidant Activity
}

\author{
Carina A. Rodrigues, ${ }^{\oplus a}$ Antonio E. Nicácio, ${ }^{a}$ Isabel C. S. F. Jardim, ${ }^{b}$ \\ Jesuí V. Visentainer ${ }^{*, a}$ and Liane Maldaner ${ }^{a}$ \\ ${ }^{a}$ Departamento de Química, Universidade Estadual de Maringá (UEM), \\ Avenida Colombo, 5790, 87020-900 Maringá-PR, Brazil \\ ${ }^{b}$ Instituto de Química, Universidade Estadual de Campinas (UNICAMP), \\ CP 6154, 13083-970 Campinas-SP, Brazil
}

\begin{abstract}
In the present work, a fast, easy and efficient analytical method was developed and validated for the determination of phenolic compounds (4-hydroxybenzoic, vanillic, caffeic, $p$-coumaric, sinapic, ferulic and ellagic acids, and naringenin) in red sweet pepper. Extraction of phenolic compounds was carried out using the quick, easy, cheap, effective, rugged and safe (QuEChERS) method, followed by separation and detection using ultra-high performance liquid chromatography tandem mass spectrometry (UHPLC-MS/MS). When the acetate version of the QuEChERS method was used, higher amounts of the phenolic compounds were extracted. In the dispersive solid phase extraction (d-SPE) clean-up step, combination of $50 \mathrm{mg}$ of octadecylsilane (C18) and $7.5 \mathrm{mg}$ of graphitized carbon black (GCB), resulted in the greatest removal of interferents, especially carotenoids, without significant retention of phenolic compounds. The recoveries for the proposed method were $82-103 \%$, the limits of quantification were $2-150 \mu \mathrm{g} \mathrm{kg}^{-1}$, and the precision values expressed in terms of relative standard deviation (RSD) were $\leq 15 \%$. The method developed was successfully applied to the analysis of different red sweet pepper cultivars.
\end{abstract}

Keywords: QuEChERS method, sorbents, antioxidant activity, UHPLC-MS/MS, validation

\section{Introduction}

Fruits and vegetables are natural sources with a high content of antioxidant compounds, including vitamins, carotenoids, minerals and phenolic compounds, which have been correlated with beneficial health effects with regular dietary intakes. ${ }^{1-3}$ Antioxidant compounds can prevent or delay the effects of free radicals (reactive oxygen and nitrogen species), which are constantly generated from cell metabolism, and can cause damage to proteins, deoxyribonucleic acid (DNA), ribonucleic acid (RNA), sugars and lipids. ${ }^{4-6}$

Phenolic compounds are the largest group of antioxidant compounds, with more than 8,000 molecules already isolated and described in plants, including flavonoids and phenolic acids. ${ }^{1,7,8}$ These compounds are associated with the prevention of numerous diseases, such as cancers, cardiovascular diseases, autoimmune diseases, brain

*e-mail: jesuiv@gmail.com dysfunction, cataracts, obesity, type 2 diabetes and age related oxidative problems. ${ }^{1,3,7,9}$

The Solanaceae plant family is one of the largest and most diverse plant families found throughout the world, but it is the most abundant and widely distributed in tropical and temperate regions. ${ }^{10,11}$ The most economically important crops of this family include potato (Solanum tuberosum), tomato (S. lycopersicum), eggplant (S. melongena), tobacco (Nicotiana tabacumn and N. rustica) and pepper (Capsicum species)..$^{10,12-14}$

The genus Capsicum includes numerous species of sweet and hot peppers, with Capsicum annuиm L. the world's most widely grown specie of the five domesticated species, which also includes $C$. baccatum L., C. chinense Jacq., $C$. frutescens $\mathrm{L}$. and $C$. pubescens. ${ }^{15,16}$ The different species in this genus are used as spices, vegetables, and/or as medicines, and recent studies have shown that they are also a rich source of bioactive compounds. ${ }^{3,16,17}$ Several antioxidant compounds have been characterized in both sweet and hot peppers, such as carotenoids, ${ }^{18,19}$ 
vitamin C, ${ }^{18,20}$ capsaicinoids, ${ }^{20-22}$ fatty acids (linoleic acid, palmitic acid and $\alpha$-linolenic acid), ${ }^{23}$ tocopherols, ${ }^{23}$ and especially phenolic compounds (such as flavonoids and phenolic acids). ${ }^{19,20,22,24-26}$

Over the years, different methods have been used to determine phenolic compounds in plant matrices. Several works ${ }^{25,27-29}$ reported the quantification of these compounds as total phenolic, flavonoid and anthocyanin content, or as total antioxidant capacity. However, for individual identification and quantification, chromatographic techniques based on liquid chromatography coupled to ultraviolet-visible spectrophotometry (UV-Vis) and mass spectrometry detectors have been widely used. . $5,30-32^{-32}$

The extraction step also plays a crucial role in the individual identification and quantification of phenolic compounds. Currently, there is a trend in the use of sample preparation techniques that are easier to perform, faster, inexpensive and that promote clean-up of the sample extract. ${ }^{33}$ The quick, easy, cheap, effective, rugged and safe (QuEChERS) extraction method is a promising alternative for the extraction of phenolic compounds in complex matrices such as plant matrices. This method was first proposed by Anastassiades et al. ${ }^{34}$ for the analysis of multi-residues of pesticides in fruits and vegetables. The QuEChERS method remains extensively used for this purpose since modifications can be introduced according to the characteristics of the analyte / matrix to be analyzed, i.e., addition of acetate or citrate in the extraction / partitioning step and the use of alternative sorbents such as octadecylsilane (C18) and graphitized carbon black (GCB) in the dispersive solid phase extraction (d-SPE) clean-up step. Furthermore, the QuEChERS extraction method has been shown to be effective for the analysis of other groups of compounds, including mycotoxins,,$^{35}$ tocopherols, and sitosterols ${ }^{36}$ in pomegranate, seed, and nuts, respectively. However, for the analysis of phenolic compounds in fruits and vegetables, the QuEChERS extraction method has not been widely applied. ${ }^{26,37}$

Thus, the aim of this study was to determine the levels of 4-hydroxybenzoic, caffeic, $p$-coumaric, ferulic, ellagic, sinapic and vanillic acids, and naringenin from four different cultivars of Capsicum аппиит L. ("gaston", "pampa", "rialto" and "Italian sweet"). A sample preparation step based on a QuEChERS extraction method, followed by ultra-high performance liquid chromatography tandem mass spectrometry (UHPLC-MS/MS) analysis, was optimized and validated. As a complementary study, the phenolic content previously determined during the clean-up step optimization was compared to the total phenolic content (TPC) and antioxidant activity measured by spectrophotometric and spectrofluorimetric methods (2,2-diphenyl-1-picrylhydrazyl ( $\left.\mathrm{DPPH}^{*}\right), 2,2^{\prime}$ '-azinobis(3-ethylbenzothiazoline-6-sulfonic acid) diammonium salt $\left(\mathrm{ABTS}^{*+}\right.$ ) and oxygen radical absorbance capacity (ORAC)).

\section{Experimental}

\section{Standards, solvents and reagents}

Phenolic compound standards, 4-hydroxybenzoic acid (HBA), caffeic acid (CA), $p$-coumaric acid (PCA), ferulic acid (FA), ellagic acid (EA), and naringenin (NAR) were purchased from Sigma-Aldrich (Saint Louis, USA), and sinapic acid (SA) and vanillic acid (VA) were purchased from Fluka (Saint Louis, USA). All reference standards had purities greater than $95 \%$. Stock standard solutions of the phenolic compounds were prepared in methanol at concentration levels of $1000 \mathrm{mg} \mathrm{L}^{-1}$ and stored at $-18^{\circ} \mathrm{C}$. Working standard mixture solutions were prepared by appropriate dilution of the stock solutions in methanol.

The reagents used in the antioxidant methods and the total phenolic content analysis, $( \pm)$-6-hydroxy2,5,7,8-tetramethylchromane-2-carboxylic acid (Trolox), $\mathrm{DPPH}^{\circ}, \mathrm{ABTS}^{++}, 2,2$-azobis(2-methylpropanimidamide) dihydrochloride (AAPH), and Folin-Ciocalteu reagent, were supplied from Sigma-Aldrich (Saint Louis, USA). Fluorescein was obtained from Fluka (Saint Louis, USA).

High performance liquid chromatography (HPLC)grade methanol and acetonitrile were purchased from J. T. Baker (Edo. de Mexico, Mexico). Ultrapure water was obtained from a Milli-Q ultrapure water purification system (Millipore, USA). Formic acid, used in the mobile phase, and acetic acid, used in the extraction procedure, were purchased from Sigma-Aldrich (Saint Louis, USA) and Fluka (Saint Louis, USA), respectively.

The salts used in this study were of analytical reagent grade. Disodium hydrogencitrate sesquihydrate $\left(\mathrm{C}_{6} \mathrm{H}_{6} \mathrm{Na}_{2} \mathrm{O}_{7} \cdot 1.5 \mathrm{H}_{2} \mathrm{O}\right)$ was purchased from Alfa Aesar (Ward Hill, USA). Sodium citrate tribasic dihydrate $\left(\mathrm{C}_{6} \mathrm{H}_{5} \mathrm{Na}_{3} \mathrm{O}_{7} \cdot 2 \mathrm{H}_{2} \mathrm{O}\right)$, anhydrous magnesium sulfate $\left(\mathrm{MgSO}_{4}\right)$ and anhydrous sodium acetate $\left(\mathrm{CH}_{3} \mathrm{COONa}\right)$ were purchased from J. T. Baker (Edo. de Mexico, Mexico). Sodium chloride $(\mathrm{NaCl})$ was purchased from Merck (Darmstadt, Germany). The sorbents, Bondesil primary secondary amine (PSA) $(40 \mu \mathrm{m})$ and GCB, were purchased from Agilent Technologies (Santa Clara, USA). Octadecylsilane (C18) was purchased from Supelco (Bellefonte, USA). The fluorinated sorbent was produced and characterized by the Institute of Chemistry, from the University of Campinas (São Paulo, Brazil). 


\section{Samples}

For this study, four different cultivars of red sweet peppers called "gaston", "pampa", "rialto" and "Italian sweet", all belonging to the species C. апnиum L., were purchased from a local market in Maringá (232 $25^{\prime} \mathrm{S}$, 515' W), Paraná, Brazil. The QuEChERS method optimization and validation study was carried out with "gaston" cultivar, and the other cultivars were used in the method applicability.

Before analysis, the samples were washed in tap water, and the placenta along with the seeds was manually removed from the fruit. After separation of the parts, the fruits were crushed to form a paste, packed under vacuum and stored in a freezer at $-18^{\circ} \mathrm{C}$ until analysis.

\section{Optimization of the QuEChERS method}

Optimization of the QuEChERS method for the extraction of phenolic compounds from red sweet pepper was based on the different versions of the QuEChERS method, including the original method described by Anastassiades et al.,${ }^{34}$ the acetate buffer method studied by Lehotay et $a l .^{38}$ and the citrate buffer modification described by Anastassiades et al. ${ }^{39}$ The extraction, partitioning and clean-up steps were evaluated. For all evaluated methods, $10.0 \mathrm{~g}$ of the sample were transferred to a $50 \mathrm{~mL}$ polypropylene centrifuge tube and extracted following the proposed methodologies (QuEChERS original, QuEChERS acetate and QuEChERS citrate). After addition of the partition salts, the tubes were shaken by vortex AP 56 (Phoenix, Araraquara, Brazil) for $1 \mathrm{~min}$ and immediately centrifuged for $10 \mathrm{~min}$ at $4529 \times \mathrm{g}$ in a Harrier 18/80R centrifuge (Sanyo MSE, London, UK). For optimization of the extraction/partition step, the different QuEChERS methods were evaluated using the same d-SPE clean-up step (25 mg of PSA).

After optimizing the extraction/partition step, the d-SPE clean-up step was also optimized. For this, different amounts of sorbent used individually or in combination were evaluated, as shown in Table 1.

For all clean-up procedures, the mixture was shaken for $1 \mathrm{~min}$ and centrifuged for $10 \mathrm{~min}$ at $4529 \times \mathrm{g}$. Then, the supernatant was filtered through a polytetrafluoroethylene (PTFE) syringe filter $(13 \mathrm{~mm}$ diameter and $0.22 \mu \mathrm{m}$ pore) before UHPLC-MS/MS analysis. The same aliquot of the extract was used to determine the TPC and antioxidant activity (DPPH', ABTS $^{\circ+}$ and ORAC methods) and to evaluate the clean-up efficiency from the spectrophotometric analysis.

Finally, the validated QuEChERS method for the extraction of phenolic compounds from red sweet pepper
Table 1. Sorbents used in the d-SPE clean-up step

\begin{tabular}{lcc}
\hline & Test & Sorbent / mg \\
\hline \multirow{2}{*}{ QuEChERS acetate } & T1 & $25 \mathrm{PSA}$ \\
& T2 & $50 \mathrm{PSA}$ \\
T3 & $25 \mathrm{C} 18$ \\
& T4 & $50 \mathrm{C} 18$ \\
& T5 & $50 \mathrm{C} 18+7.5 \mathrm{GCB}$ \\
& T6 & $50 \mathrm{C} 18+2.5 \mathrm{GCB}$ \\
& $\mathrm{T} 7$ & $50 \mathrm{C} 18+10 \mathrm{~F}$ \\
\hline
\end{tabular}

QuEChERS: quick, easy, cheap, effective, rugged and safe; PSA: primary secondary amine; C18: octadecylsilane; GCB: graphitized carbon black; F: fluorinated sorbent.

was as follows: $10.0 \mathrm{~g}$ of the sample was transferred to a $50 \mathrm{~mL}$ polypropylene centrifuge tube. Then $10.0 \mathrm{~mL}$ of $1 \%(\mathrm{v} / \mathrm{v})$ acetic acid in acetonitrile was added, and the tubes were shaken for $1 \mathrm{~min}$. Next, anhydrous $\mathrm{MgSO}_{4}(4.0 \mathrm{~g})$ and $\mathrm{CH}_{3} \mathrm{COONa}(1.0 \mathrm{~g})$ were added, and the tubes were shaken for $1 \mathrm{~min}$ and immediately centrifuged for $10 \mathrm{~min}$ at $4529 \times \mathrm{g}$. For the clean-up step, $1.0 \mathrm{~mL}$ of the supernatant was transferred to a $15 \mathrm{~mL}$ polypropylene centrifuge tube containing $150 \mathrm{mg}$ of anhydrous $\mathrm{MgSO}_{4}, 50 \mathrm{mg}$ of $\mathrm{C} 18$ and $7.5 \mathrm{mg}$ of GCB. The mixture was shaken for $1 \mathrm{~min}$ and centrifuged for $10 \mathrm{~min}$ at $4529 \times \mathrm{g}$. Then, the supernatant was filtered through a PTFE syringe filter $(13 \mathrm{~mm}$ diameter and $0.22 \mu \mathrm{m}$ pore) before UHPLC-MS/MS analysis.

Antioxidant activity methods and total phenolic content

\section{$\mathrm{DPPH}^{\bullet}$ scavenging method}

The DPPH radical scavenging method was carried out according to Ma et al..$^{40}$ The extracts obtained after optimization of the clean-up step $(25 \mu \mathrm{L})$ were added to $2 \mathrm{~mL}$ of $6.25 \times 10^{-5} \mathrm{~mol} \mathrm{~L}^{-1} \mathrm{DPPH}$ radical methanolic solution. The solutions were incubated in the dark for $30 \mathrm{~min}$, and then the absorbance was measured at a wavelength of $517 \mathrm{~nm}$ in a Genesys 10S UV-Vis spectrophotometer (Thermo Fisher Scientific, Madison, USA). Trolox

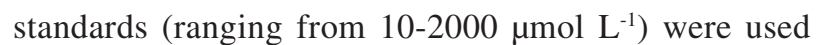
to prepare the analytical curve $(y=-0.0003 x+0.6656$, coefficient of determination $\left.\left(r^{2}\right)=0.990\right)$, and the results were expressed as micromoles of Trolox equivalents per $100 \mathrm{~g}$ of fresh weight ( $\mu \mathrm{mol}$ TE $\left.100 \mathrm{~g}^{-1} \mathrm{FW}\right)$.

\section{ABTS $^{*+}$ scavenging method}

The ABTS radical scavenging method was carried out according to Rufino et al. ${ }^{41}$ The ABTS cation radical solution was prepared by reacting $7 \mathrm{mmol} \mathrm{L}^{-1}$ of ABTS with $2.45 \mathrm{mmol} \mathrm{L}^{-1}$ of potassium persulfate at room temperature in the dark for $16 \mathrm{~h}$. This solution was then diluted with 
ethanol to obtain an absorbance of $0.700 \pm 0.020$ at $734 \mathrm{~nm}$. Approximately $30 \mu \mathrm{L}$ aliquots of the extracts obtained after the clean-up optimization step were added to $3 \mathrm{~mL}$ of the diluted ABTS $^{\cdot+}$ solution. The solutions were incubated in the dark for $6 \mathrm{~min}$, and then the absorbance was measured in a Genesys 10S UV-Vis spectrophotometer (Thermo Fisher Scientific, Madison, USA). Trolox standards (ranging from $\left.10-1500 \mu \mathrm{mol} \mathrm{L}^{-1}\right)$ were used to prepare the analytical curve $\left(y=-0.0004 x+0.7671, \mathrm{r}^{2}=0.998\right)$, and the results were expressed as $\mu$ mol TE $100 \mathrm{~g}^{-1} \mathrm{FW}$.

\section{ORAC method (oxygen radical absorbance capacity)}

Determination of the antioxidant activity from the ORAC method was performed according to Ou et al. ${ }^{42} \mathrm{~A}$ fluorescein stock solution $\left(1.03 \mathrm{mmol} \mathrm{L}^{-1}\right)$ was prepared in a phosphate buffer solution (dibasic potassium phosphate and monobasic potassium phosphate, $75 \mathrm{mmol} \mathrm{L}^{-1}$, $\mathrm{pH}$ 7.4) and diluted to obtain the working solution (40 nmol L-1). The AAPH working solution was prepared daily by adding $434 \mathrm{mg}$ of AAPH to $10 \mathrm{~mL}$ of phosphate buffer $\left(75 \mathrm{mmol} \mathrm{L}^{-1}\right)$ to obtain a final concentration of $161 \mathrm{mmol} \mathrm{L}^{-1}$. Adequate dilution of extracts obtained after the clean-up step optimization were performed in the phosphate buffer solution and $25 \mu \mathrm{L}$ of these solutions were transferred to a microplate with 96 wells and $150 \mu \mathrm{L}$ of the fluorescein solution $\left(40 \mathrm{nmol} \mathrm{L}{ }^{-1}\right)$ was added. The microplate was heated at $37{ }^{\circ} \mathrm{C}$ for $5 \mathrm{~min}$. Then, $25 \mu \mathrm{L}$ of the AAPH working solution (161 $\left.\mathrm{mmol} \mathrm{L}^{-1}\right)$ was added and the fluorescence was recorded immediately, with $485 \mathrm{~nm}$ for the excitation wavelength and $535 \mathrm{~nm}$ for the emission wavelength. The fluorescence was monitored kinetically and recorded in $1 \mathrm{~min}$ for $30 \mathrm{~min}$ in a Victor ${ }^{\mathrm{TM}} \mathrm{X} 4$ multimode plate reader (PerkinElmer, Waltham, USA). Trolox standard solutions (ranging from 0.5-10.0 $\mu \mathrm{mol} \mathrm{L} \mathrm{L}^{-1}$ ) were used to prepare the analytical curve $\left(y=0.6059 x+2.4954, \mathrm{r}^{2}=0.997\right)$, and the concentration calculations were based on the area under the fluorescence curve. The results were expressed as $\mu$ mol TE $100 \mathrm{~g}^{-1} \mathrm{FW}$.

Total phenolic content (TPC)

The total phenolic content (TPC) was determined using the Folin-Ciocalteu reagent ${ }^{43}$ as described by Shahidi and Naczk. ${ }^{44}$ For this, the extracts obtained after optimization of the clean-up step $(250 \mu \mathrm{L})$ were mixed with $250 \mu \mathrm{L}$ of the Folin-Ciocalteu reagent (diluted in distilled water, 1:1 v:v). Then, $500 \mu \mathrm{L}$ of saturated sodium carbonate solution and $4 \mathrm{~mL}$ of distilled water were added. The solutions were incubated in the dark for $25 \mathrm{~min}$, centrifuged for $10 \mathrm{~min}$ at $4529 \times \mathrm{g}$, and the absorbance was measured at $725 \mathrm{~nm}$ in a Genesys 10S UV-Vis spectrophotometer (Thermo Fisher Scientific,
Madison, USA). Gallic acid standard solutions (ranging from $10-200 \mathrm{mg} \mathrm{L}^{-1}$ ) were used to prepare the analytical curve $\left(y=0.0059 x+0.1806, \mathrm{r}^{2}=0.991\right)$. The results were expressed as milligrams of gallic acid equivalents per $100 \mathrm{~g}$ of fresh weight (mg GAE $100 \mathrm{~g}^{-1} \mathrm{FW}$ ).

\section{Clean-up efficiency evaluation by spectrophotometric analysis}

Spectrophotometric analysis of the extracts obtained after each sorbent evaluation in d-SPE clean-up for the QuEChERS acetate method was carried out using a UV-Vis Cary 60 spectrophotometer (Agilent Technologies, Santa Clara, USA). The extracts were scanned in the wavelength range of 200-800 $\mathrm{nm}$. Before scanning, $100 \mu \mathrm{L}$ of each extract was diluted in $2 \mathrm{~mL}$ of acetonitrile and added to a quartz cuvette. Blank samples were recorded with acetonitrile.

\section{UHPLC-MS/MS analysis}

A UPLC Acquity H-CLASS coupled to a Xevo TQD triple-quadrupole mass spectrometer equipped with a $\mathrm{Z}$ spray $^{\mathrm{TM}}$ ESI interface operating in both positive and negative mode (Waters, Milford, USA) was used to carry out the chromatographic analysis. Chromatographic separation was performed using a $1.7 \mu \mathrm{m}$ Acquity UPLC ${ }^{\circledR}$ BEH C18 column $(50 \times 2.1 \mathrm{~mm}$ i.d. $)$ from Waters at a

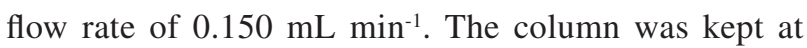
$30 \pm 1{ }^{\circ} \mathrm{C}$ and the sample injection volume was $1.5 \mu \mathrm{L}$. The mobile phase was (A) $\mathrm{H}_{2} \mathrm{O}$ (acidified with $0.1 \%$ formic acid) and (B) $\mathrm{MeOH}$. Gradient elution was used and the organic solvent $(\mathrm{MeOH})$ percentage was changed linearly as follows: $0-0.01 \mathrm{~min}(10 \% \mathrm{~B}), 1 \mathrm{~min}(30 \% \mathrm{~B})$, $1.5 \min (40 \% \mathrm{~B}), 2 \mathrm{~min}(50 \% \mathrm{~B}), 4-7 \mathrm{~min}(60 \% \mathrm{~B}), 7.5 \mathrm{~min}$ $(50 \% \mathrm{~B}), 8 \mathrm{~min}(30 \% \mathrm{~B})$, and $8.5-13 \mathrm{~min}(10 \% \mathrm{~B})$. The mass spectrometer was operated using an electrospray (ESI) source in negative mode. ESI conditions were as follows: capillary voltage, $3.0 \mathrm{kV}$; extractor voltage, $3.0 \mathrm{~V}$; source temperature, $130{ }^{\circ} \mathrm{C}$; desolvation gas temperature, $550{ }^{\circ} \mathrm{C}$; cone gas (nitrogen) flow of $50 \mathrm{~L} \mathrm{~h}^{-1}$ and desolvation gas (also nitrogen) flow of $700 \mathrm{~L} \mathrm{~h}^{-1}$. Argon (99.9\%) from White Martins (Rio de Janeiro, Brazil) was used as the collision gas at a constant pressure of $3.00 \times 10^{-3} \mathrm{mbar}$. The mass spectrometer was operated in MS/MS mode using selected reaction monitoring (SRM). The most intense ion transition was selected for quantification and the second one for qualification. Specific MS/MS parameters for each phenolic compound are shown in Table 2. MassLynx and QuanLynx software version 4.1 (Waters) were used for instrument control and data processing. 
Table 2. Chemical information, selected ion transitions and instrumental parameters for the phenolic compounds under study

\begin{tabular}{|c|c|c|c|c|c|c|c|c|c|}
\hline Phenolic compound & Chemical structure & Chemical class & $\mathrm{p} K_{\mathrm{a}}$ & $\mathrm{t}_{\mathrm{R}} / \min$ & ESI mode & $\begin{array}{c}\text { SRM } \\
\text { transition } \\
(m / z)^{\mathrm{a}}\end{array}$ & $\begin{array}{c}\text { Cone } \\
\text { voltage / V }\end{array}$ & $\begin{array}{l}\text { Collision } \\
\text { energy / eV }\end{array}$ & $\begin{array}{l}\text { Dwell } \\
\text { time / s }\end{array}$ \\
\hline $\begin{array}{l}\text { 4-Hydroxybenzoic } \\
\text { acid }\end{array}$ & & phenolic acid & $\begin{array}{l}4.6 \\
9.5\end{array}$ & 4.04 & - & $136.8>92.9$ & 25 & 15 & 0.05 \\
\hline Vanilic acid & & phenolic acid & $\begin{array}{l}4.1 \\
8.9\end{array}$ & 4.46 & - & $\begin{array}{l}166.9>151.9 \\
166.9>107.9\end{array}$ & $\begin{array}{l}35 \\
35\end{array}$ & $\begin{array}{l}17 \\
13\end{array}$ & 0.05 \\
\hline Caffeic acid & & phenolic acid & $\begin{array}{l}4.4 \\
8.3\end{array}$ & 4.46 & - & $179>135$ & 38 & 20 & 0.05 \\
\hline$p$-Coumaric acid & & phenolic acid & $\begin{array}{l}4.3 \\
8.8\end{array}$ & 5.05 & - & $\begin{array}{c}162.9>118.9 \\
162.9>92.9\end{array}$ & $\begin{array}{l}28 \\
28\end{array}$ & $\begin{array}{l}14 \\
28\end{array}$ & 0.07 \\
\hline Sinapic acid & & phenolic acid & 4.5 & 5.10 & - & $\begin{array}{c}222.9>193 \\
222.9>148.9\end{array}$ & $\begin{array}{l}36 \\
36\end{array}$ & $\begin{array}{l}21 \\
24\end{array}$ & 0.07 \\
\hline Ferulic acid & & phenolic acid & $\begin{array}{l}4.6 \\
8.6\end{array}$ & 5.14 & - & $\begin{array}{l}192.9>133.9 \\
192.9>177.9\end{array}$ & $\begin{array}{l}30 \\
30\end{array}$ & $\begin{array}{l}13 \\
17\end{array}$ & 0.07 \\
\hline Ellagic acid & & phenolic acid & $\begin{array}{c}6.3 \\
11.2\end{array}$ & 5.50 & - & $\begin{array}{l}301>229 \\
301>284\end{array}$ & $\begin{array}{l}60 \\
60\end{array}$ & $\begin{array}{l}31 \\
28\end{array}$ & 0.07 \\
\hline Naringenin & & flavonoid & $\begin{array}{l}6.7 \\
9.1\end{array}$ & 6.70 & - & $\begin{array}{l}271>150.9 \\
271>118.9\end{array}$ & $\begin{array}{l}36 \\
36\end{array}$ & $\begin{array}{l}17 \\
32\end{array}$ & 0.07 \\
\hline
\end{tabular}

${ }^{a}$ The first transition of each compound was used for quantification and the second one for qualification purposes. $t_{\mathrm{R}}$ : retention time; ESI: electrospray; SRM: selected reaction monitoring.

\section{Method validation}

Linearity, accuracy, inter and intra-day precision, limit of detection (LOD), limit of quantification (LOQ) and matrix effect (ME) were evaluated during the validation study according to the European SANTE/11945/2015 guidelines ${ }^{45}$ Linearity was evaluated using the standard addition method, analyzing red sweet pepper extracts at six levels of concentration (6-5400 $\left.\mu \mathrm{g} \mathrm{kg}^{-1}\right)$. In the same way, the endogenous amounts of the target phenolic compounds were also estimated. To evaluate the method accuracy, recovery studies were carried out at two concentration levels (determined for each phenolic compound after the estimation of the endogenous amount) by spiking five sample extracts at each concentration level. The quantification was performed using the standard addition method. The precision, intra-day and inter-day (evaluated on two consecutive days) were carried out at the same concentration levels of the recovery studies, and expressed in terms of relative standard deviation (RSD). LOD and LOQ were calculated as the quantity of analyte able to produce a chromatographic peak three and ten 
times higher, respectively, than the noise of the baseline in a chromatogram of a non-fortified sample, after to estimate the endogenous amount. The ME values (\%) for each phenolic compound were calculated (equation 1) by comparing the slopes of the solvent and standard addition (matrix) analytical curves obtained at the same concentration levels, as described by Kaczynski: ${ }^{46}$

$\% \mathrm{ME}=\left(\frac{\text { slope matrix }}{\text { slope solvent }}-1\right) \times 100$

The matrix effect may be present as positive or negative values, indicating enhancement or suppression of the signals, respectively. Values of $\mathrm{ME} \leq \pm 20 \%$ indicated no matrix effect, while ME values $\geq \pm 50 \%$ indicate a strong matrix effect. ${ }^{47}$

\section{Application}

Four different cultivars of red sweet peppers ("gaston", "pampa", "rialto" and "Italian sweet") were analyzed with the proposed method.

\section{Statistical analysis}

Data is presented as the mean and standard deviation (SD). Assistat ${ }^{\circledR}$ v. 7.7 software $^{48}$ was used for analysis of the Tukey's test $(p<0.05)$.

\section{Results and Discussion}

Optimization of the QuEChERS method for the extraction of phenolic compounds in red sweet pepper

\section{Optimization of the extraction/partitioning steps}

The optimization of the extraction/partitioning steps was carried out by comparison of extraction performance obtained with the three versions of the QuEChERS method (original, acetate and citrate). The original QuEChERS method consisted of the addition of the partitioning salts, anhydrous magnesium sulfate, and sodium chloride, followed by extraction of compounds with no $\mathrm{pH}$ correction (i.e., $\mathrm{pH}$ of the extraction medium varies according to the $\mathrm{pH}$ of the sample). ${ }^{34}$ On the other hand, for the citrate and acetate QuEChERS methods, in addition to the partition salts, the $\mathrm{pH}$ of the extraction medium was adjusted to approximately 5.0-5.5 and 4.8, respectively. ${ }^{38,39}$ For the citrate QuEChERS method, disodium hydrogencitrate sesquihydrate and sodium citrate tribasic dehydrate salts were added, and for the acetate QuEChERS method, the extraction solvent was acidified with acetic acid and sodium acetate salt was added. ${ }^{38,39}$ Figure 1 presents the relation of the phenolic compounds extracted with the respective amounts (in means of peak area) for each QuEChERS method evaluated, keeping $25 \mathrm{mg}$ of PSA as the d-SPE sorbent for all extractions.

In Figure 1, it can be observed that 4-hydroxybenzoic, vanillic, caffeic and ellagic acids were extracted only when the QuEChERS acetate method was employed. Also, naringenin, $p$-coumaric, ferulic and sinapic acids were extracted in higher amounts compared to those obtained with the original and citrate QuEChERS methods.

The best results obtained with the QuEChERS acetate method can be explained by the lower $\mathrm{pH}$ with this version (4.8) when compared to the QuEChERS citrate method (5.0-5.5) and to the QuEChERS original method in which the measured sample $\mathrm{pH}$ was approximately 5.15. Assuming that phenolic compounds are more stable at lower $\mathrm{pH}$ values since the phenol-phenolate equilibrium shifts toward the less polar phenol form, from the values of $\mathrm{p} K_{\mathrm{a}}$ (Table 2), the acidification of the sample during extraction/partitioning steps promotes the extraction of the compounds to the organic phase (acetonitrile). ${ }^{49,50}$

\section{Optimization of the d-SPE clean-up step}

To obtain a final extract free of undesirable interfering compounds, the d-SPE clean-up step was optimized evaluating different sorbents used individually or in combination, as presented in Table 1 .

Several sorbents have been reported as d-SPE cleanup sorbents in plant matrices, especially PSA, C18 and GCB. ${ }^{51-57}$ Alternatively, sorbents such as oasis HLB $^{\circledR}$, chitosan and fluorinated sorbent $(\mathrm{F})$ have already been used. ${ }^{58-60}$ Among the commonly used sorbents cited above, PSA is used for removing sugars, fatty acids, organic acids, lipids and some polar pigments, ${ }^{34,61}$ while $\mathrm{C} 18$ sorbent is used for removing nonpolar compounds, such as lipids and fatty acids, from fatty matrices (lipid content $>2 \%$ ). ${ }^{62} \mathrm{GCB}$, on the other hand, has a strong affinity for planar molecules and is used for removing some pigments (e.g., chlorophyll, carotenoids) and sterols. ${ }^{34,63}$ The alternative sorbent, oasis HLB $^{\circledR}$ polymeric sorbent, has a modified surface with divinylbenzene (nonpolar) and an $N$-vinylpyrrolidone (polar), which is used for the extraction of acidic, basic and neutral compounds with medium to high polarity. ${ }^{64}$ Chitosan is a cationic polysaccharide that contains chemical reactive groups (hydroxyl, acetamido or amino functions) in polymer chains, which provides excellent selectivity with aromatic compounds and metals,${ }^{65}$ and the fluorinated sorbent displays unique selectivity of the specific properties of the $\mathrm{C}-\mathrm{F}$ bonds that increase the interaction with polar compounds. ${ }^{66}$ 


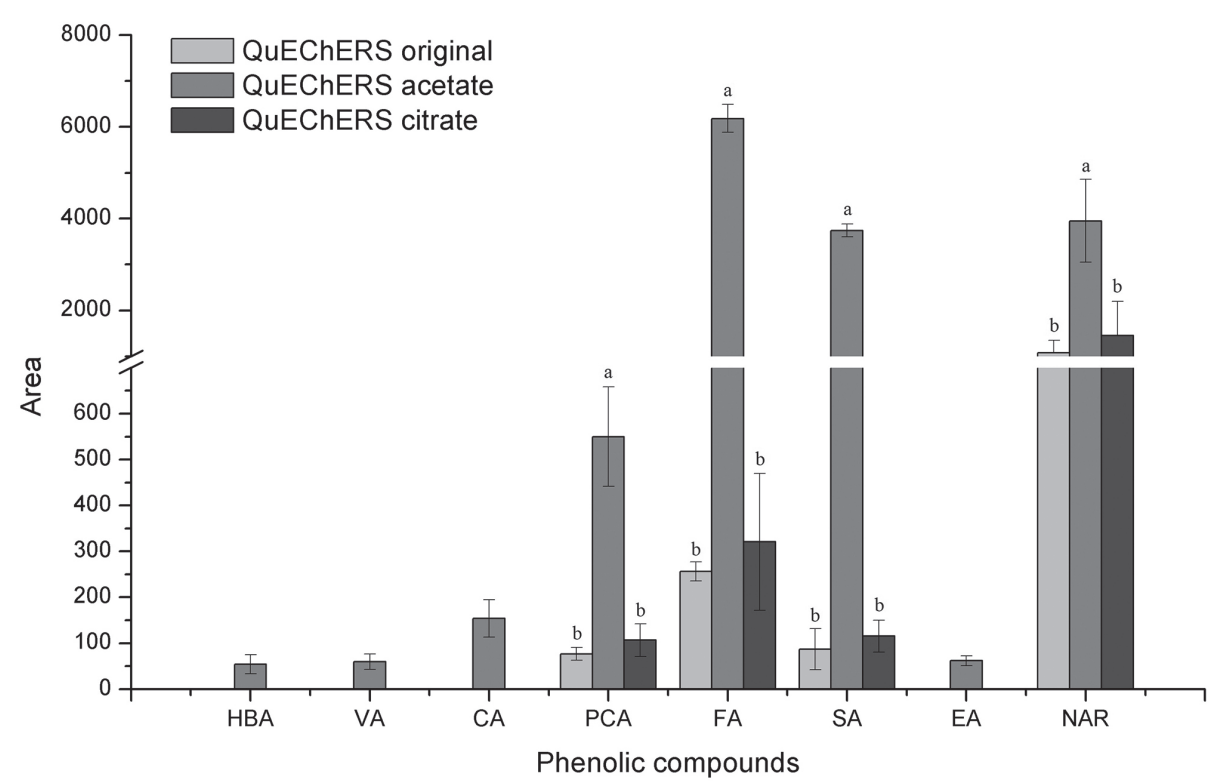

Figure 1. Evaluation of the extraction efficiency for each QuEChERS method evaluated (original, acetate and citrate), keeping $25 \mathrm{mg}$ of PSA as the d-SPE sorbent for all extractions. Data given as the mean peak area \pm the standard deviation $(n=3)$. HBA: 4-hydroxybenzoic acid; VA: vanillic acid; CA: caffeic acid; PCA: $p$-coumaric acid; FA: ferulic acid; SA: sinapic acid; EA: ellagic acid; NAR: naringenin. The QuEChERS methods followed by the same letter do not differ statistically from each other by the Tukey's test $(p<0.05)$.

Efficiency results for the d-SPE clean-up step (Table 1) for the QuEChERS acetate method are present in Figure 2. For most of the compounds, significantly lower amounts of the phenolic compounds were obtained when PSA was used as the clean-up sorbent ( $\mathrm{T} 1$ and $\mathrm{T} 2$ ), especially when compared with results obtained with the $\mathrm{C} 18$ sorbent (T3 and T4). Based on the numerically higher amounts for all phenolic compounds when C18 sorbent (T4) was used, subsequent experiments were carried out by combining
$50 \mathrm{mg}$ of C18 with different amounts of GCB (T5 and T6) and $\mathrm{F}$ sorbent (T7). It can be noted that when compared to the T4 test, the amounts for all phenolic compounds were numerically lower, but with no significant difference for most of the compounds.

However, these results showed that both $\mathrm{C} 18$ sorbent alone (T4) and combined with GCB (T5 and T6) and F (T7) sorbents were more adequate as clean-up sorbents compared to PSA, but did not show the effectiveness

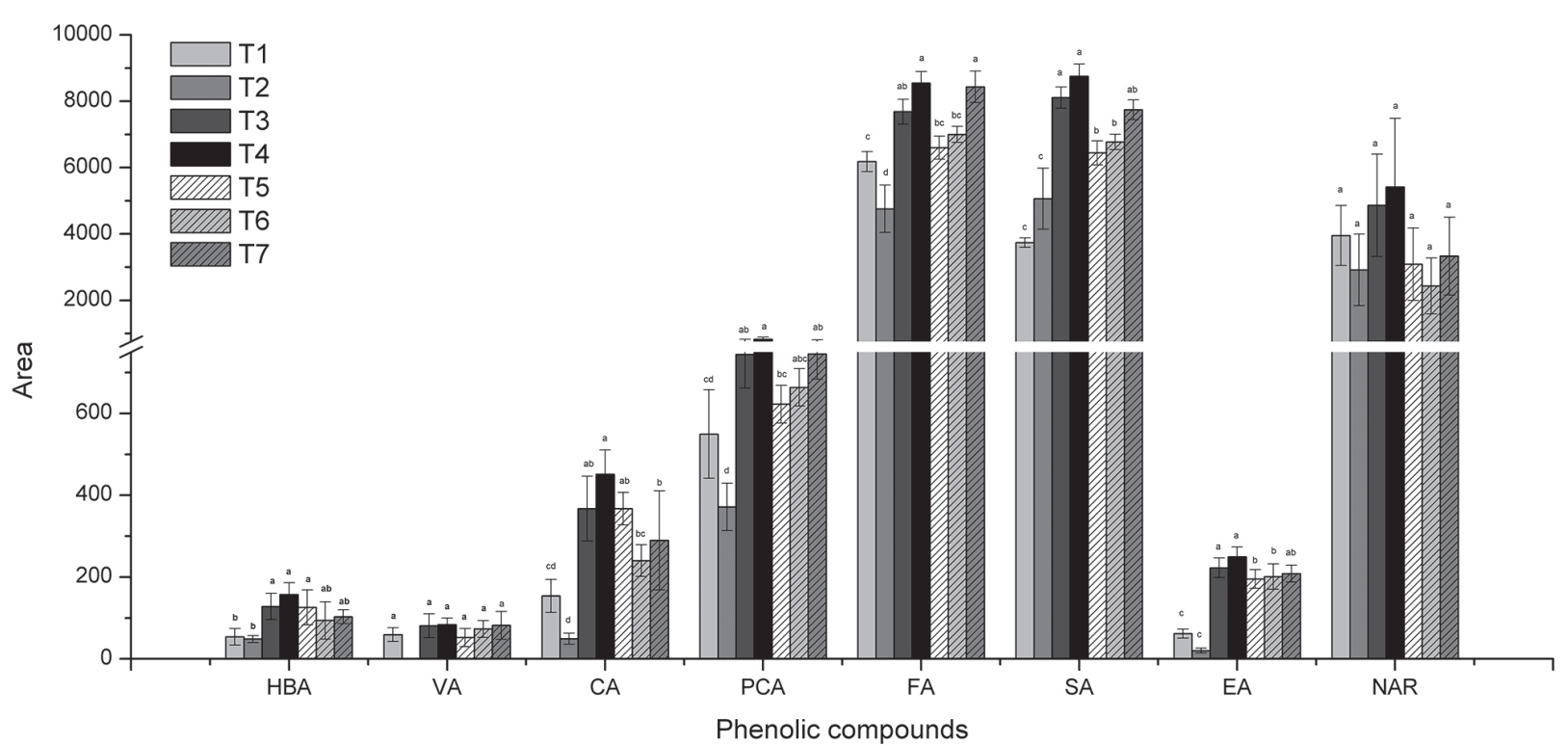

Figure 2. Evaluation of different sorbents used individually or in combination in the d-SPE clean-up step for the QuEChERS acetate method. Data given as the mean peak area \pm the standard deviation $(n=3)$. HBA: 4-hydroxybenzoic acid; VA: vanillic acid; CA: caffeic acid; PCA: $p$-coumaric acid; FA: ferulic acid; SA: sinapic acid; EA: ellagic acid; NAR: naringenin. The clean-up followed by the same letter did not differ statistically from each other by the Tukey's test $(p<0.05)$. 
on interferent removal. In this sense, the extracts of the red sweet pepper obtained after the following the clean-up steps (T4, T5, T6 and T7) were submitted to spectrophotometric analysis by scanning each extract in a wavelength range of $200-800 \mathrm{~nm}$ as presented in Figure 3 . The analysis was carried out in this region because it includes the region of maximum absorption of the carotenoids ${ }^{67}$ which are the main interferents present in extracts of red sweet pepper. ${ }^{68}$

Comparing results obtained for extracts submitted to the clean-up step (T4, T5, T6 and T7) with the extract without a clean-up step (Figure 3), a decrease in extract absorption can be noted, especially in the region of maximum carotenoid absorption (410-510 nm).

Among the clean-up sorbents evaluated, $\mathrm{C} 18$ combined with GCB (T5 and T6) presented the best results since a significant decrease in extract absorption can be observed. The efficiency of C18 sorbent combined with GCB in the removal of interferences in red sweet pepper extracts can be explained by the power of GCB in the removal of pigments, such as carotenoids, and the power of $\mathrm{C} 18$ in the removal of interferences with nonpolar characteristics.

Thus, $50 \mathrm{mg}$ of $\mathrm{C} 18$ with $7.5 \mathrm{mg}$ GCB (T5) was chosen as the sorbent combination for the d-SPE clean-up step.

\section{Evaluation of antioxidant activity and TPC before and after the clean-up step}

As a complementary study, the composition of the phenolic compounds previously determined by the QuEChERS acetate method following the several clean-up sorbents evaluated and UHPLC-MS/MS analysis (Figure 2) was compared to the TPC and antioxidant activity of these extracts obtained by traditional methods (DPPH', $\mathrm{ABTS}^{*+}$ and ORAC).

According to Figure 4, it can be observed that in all clean-up tests evaluated, the extracts showed similar antioxidant activity values and TPC values, with an exception for clean-up tests in which PSA was used as the clean-up sorbent (T1 and T2) and the analysis was carried out by $\mathrm{ABTS}^{-+}$, ORAC and TPC methods. The lower antioxidant activity and TPC values presented by $\mathrm{T} 1$ and $\mathrm{T} 2$ extracts when analyzed by $\mathrm{ABTS}^{\circ}$, ORAC and TPC methods, respectively, can be strongly correlated with the results showed in Figure 2 (i.e., the compounds were retained by the sorbent during the clean-up step). On the other hand, $\mathrm{T} 1$ and $\mathrm{T} 2$ extracts did not present the same behavior for the $\mathrm{DPPH}^{\cdot}$ method. This fact can be associated with the presence of carotenoids that also absorb in the wavelength of maximum absorption of the DPPH radical $(517 \mathrm{~nm})$, causing interferences in the results. ${ }^{69,70}$ For the other clean-up tests (T3, T4, T5, T6, T7), the same correlation was found between antioxidant activity values and the phenolic composition determined by the chromatographic analysis (i.e., higher numerical values of antioxidant activities were found, especially for extracts (T4 and T5), which also presented higher numerical values for phenolic composition). However, for the TPC analysis, no significant difference was found between the evaluated extracts.

In addition, the antioxidant activity and TPC analysis were carried out for an extract without a clean-up step as a way to verify if interferent removal in the clean-up step is occurring and, in the same way, if any removal of phenolic compounds also occurs. It can be observed that slightly higher values were obtained for the extract without

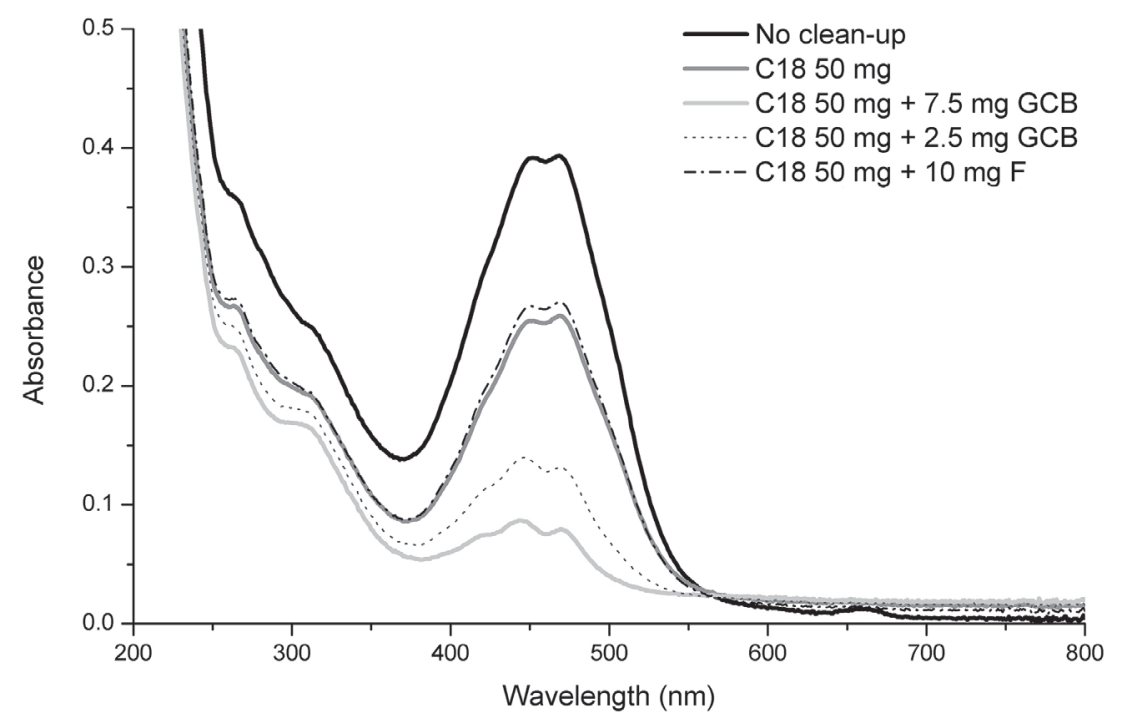

Figure 3. Spectrophotometric analysis of extracts obtained before and after each sorbent evaluated in the d-SPE clean-up for the QuEChERS acetate method. 


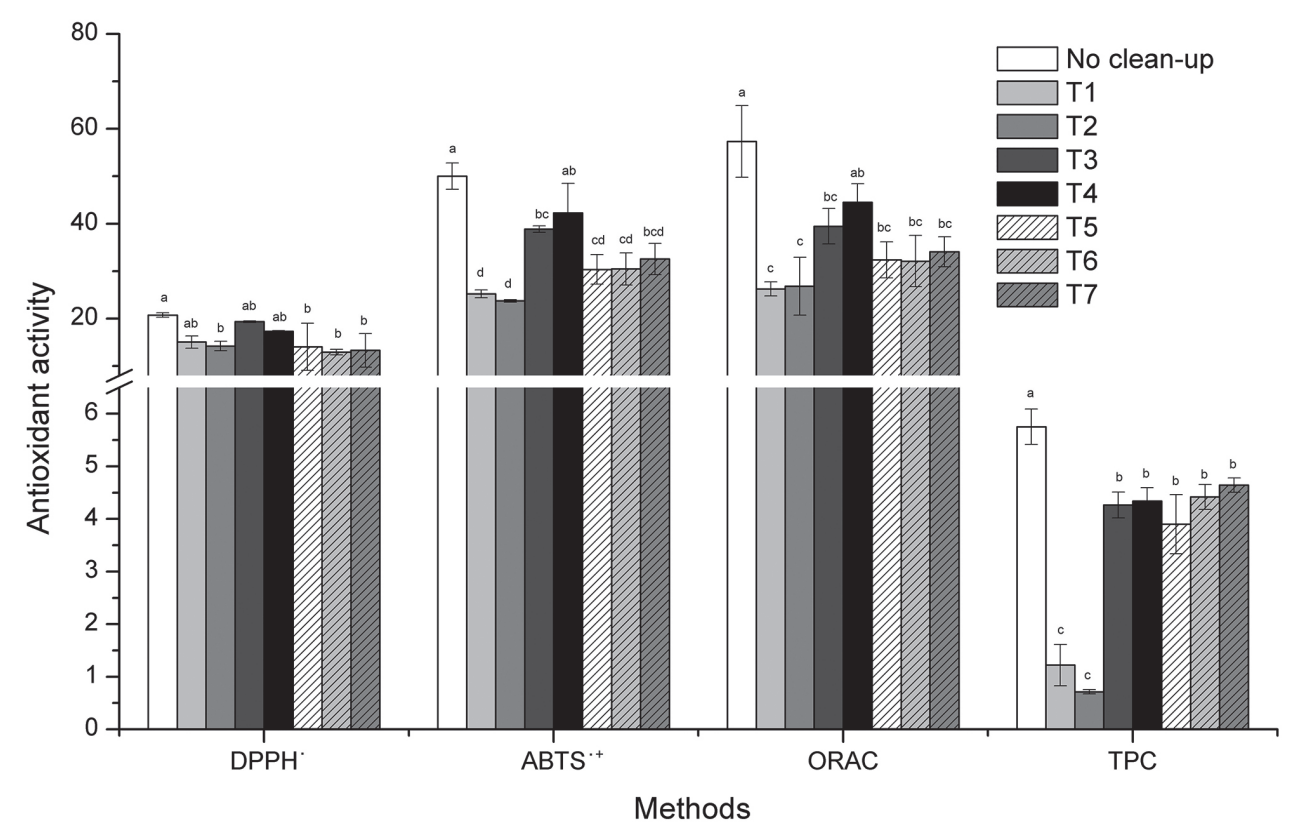

Figure 4. Antioxidant activity and TPC for extracts before and after the d-SPE clean-up step for the QuEChERS acetate method. Data given as the mean values \pm the instrumental deviation $(n=3)$. Different letters in the same method represent statistical difference according to the Tukey's test $(p<0.05)$. TPC is expressed in mg AG $100 \mathrm{~g}^{-1}$ fresh weight. The radical DPPH, the cationic radical ABTS, and the ORAC method are expressed in $\mu$ mol Trolox $100 \mathrm{~g}^{-1}$ of fresh weight.

a clean-up step when compared to T3, T4, T5, T6 and T7 extracts, suggesting that small quantities of the phenolic compounds may be retained in the clean-up sorbents and/or that other compounds (interferents) present in the extracts before the clean-up step may also contribute to the antioxidant activities and TPC values. These results suggest that the clean-up step did not compromise the determination of phenolic compounds in this study.

\section{Method validation}

The method developed was evaluated in terms of linearity, LOD, LOQ, accuracy, precision and matrix effects. Table 3 summarizes all data.

The standard addition method at six concentration levels (0.1-6.0 times the previously estimated endogenous amount) in a range of 6-5400 $\mu \mathrm{g} \mathrm{kg}^{-1}$ was used to determine method linearity. As shown in Table 3, the method developed presented good linearity for all selected phenolic compounds with correlation coefficients higher than 0.99 , and deviations of the individual points from the calibration curve lower than $\pm 20 \%$, with exception for 4-hydroxybenzoic and caffeic acids which presented residue values slightly higher. The LOD and LOQ values ranged from 0.6-45.0 and 2-150 $\mu \mathrm{g} \mathrm{kg}^{-1}$, respectively, which is satisfactory for the quantification of all phenolic compounds found in the red sweet pepper samples analyzed.

Accuracy was determined by means of recovery studies obtained at two concentration levels (as described in the Experimental section) with five replicates at each of the levels. From Table 3, it can be verified that the method presented satisfactory recoveries for all phenolic compounds studied, which ranges from $82-103 \%$ at both concentration levels evaluated.

The precision of the method was calculated in terms of intra-day and inter-day precision and expressed in terms of RSD. The results are presented in Table 3 and show that RSD values were lower than $15 \%$ for all phenolic compounds in the study.

Medium to low matrix effect values were obtained for the phenolic compounds (Table 3). With an exception for $p$-coumaric acid, all the other phenolic compounds presented signal enhancement.

\section{Application of the method}

The method developed was applied to the determination of 4-hydroxybenzoic, vanillic, caffeic, $p$-coumaric, sinapic, ferulic, and ellagic acids, and naringenin in different red sweet pepper cultivars ("gaston", "rialto", "pampa" and "Italian sweet"). As shown in Table 4, all proposed phenolic compounds were found in the different cultivars of red sweet pepper at concentration levels above the LOQ; however, the amount found for each phenolic compound was significantly different between the cultivars.

Sinapic and ferulic acids (2025 and $1420 \mu \mathrm{g} \mathrm{kg}^{-1}$ ) were found in higher concentrations for "gaston" cultivar, ellagic acid was found in higher concentration levels for "rialto" 
Table 3. Analytical performance of the developed method

\begin{tabular}{|c|c|c|c|c|c|c|c|c|c|c|c|}
\hline \multirow{2}{*}{$\begin{array}{l}\text { Phenolic } \\
\text { compound }\end{array}$} & \multirow{2}{*}{$\begin{array}{l}\text { Linear } \\
\text { range / } \\
\left(\mu \mathrm{g} \mathrm{kg}^{-1}\right)\end{array}$} & \multicolumn{3}{|c|}{ Linear regression } & \multirow{2}{*}{$\begin{array}{c}\mathrm{LOD}^{\mathrm{b}} / \\
\left(\mu \mathrm{g} \mathrm{kg}^{-1}\right)\end{array}$} & \multirow{2}{*}{$\begin{array}{c}\mathrm{LOQ}^{\mathrm{c}} / \\
\left(\mu \mathrm{gg}^{-1}\right)\end{array}$} & \multicolumn{2}{|c|}{ Recovery $/ \%$} & \multicolumn{2}{|c|}{$\begin{array}{l}\text { Inter-day precision }{ }^{\mathrm{e}} \\
\text { (RSD) } / \%\end{array}$} & \multirow{2}{*}{$\begin{array}{c}\text { Matrix } \\
\text { effect / \% }\end{array}$} \\
\hline & & $y=a x+b$ & $\mathrm{r}^{\mathrm{a}}$ & $\begin{array}{c}\text { Residual / } \\
\%\end{array}$ & & & $\mathrm{~F} 1$ & $\mathrm{~F} 2$ & $\mathrm{~F} 1$ & $\mathrm{~F} 2$ & \\
\hline $\begin{array}{l}\text { 4-Hydroxybenzoic } \\
\text { acid }\end{array}$ & $8-50$ & $y=16.911 x+296.49$ & 0.998 & -10 to +22 & 2 & 8 & $100(9)^{\mathrm{d}, \mathrm{e}}$ & $100(7)^{\mathrm{d}, \mathrm{e}}$ & 10 & 2 & +1 \\
\hline Vanillic acid & $25-150$ & $y=1.9676 x+83.048$ & 0.996 & -18 to +17 & 6 & 20 & $99(7)^{\mathrm{d}, \mathrm{e}}$ & $97(12)^{\mathrm{d}, \mathrm{e}}$ & 9 & 10 & +26 \\
\hline Caffeic acid & $7-70$ & $y=4.7552 x+176.4$ & 0.993 & -8 to +22 & 0.9 & 3 & $99(10)^{\mathrm{d}, \mathrm{e}}$ & $98(3)^{\mathrm{d}, \mathrm{e}}$ & 10 & 12 & +36 \\
\hline$p$-Coumaric acid & $6-96$ & $y=25.883 x+757.64$ & 0.999 & -16 to +17 & 0.6 & 2 & $101(6)^{\mathrm{d}, \mathrm{e}}$ & $100(4)^{\mathrm{d}, \mathrm{e}}$ & 8 & 4 & -10 \\
\hline Sinapic acid & $180-5400$ & $y=3.2934 x+4361.2$ & 0.999 & -15 to +10 & 3 & 11 & $102(6)^{\mathrm{d}, \mathrm{e}}$ & $96(7)^{\mathrm{d}, e}$ & 6 & 6 & +18 \\
\hline Ferulic acid & $120-3600$ & $y=6.1806 x+5806.1$ & 0.999 & -6 to +20 & 2 & 7 & $99(5)^{\mathrm{d}, \mathrm{e}}$ & $95(6)^{\mathrm{d}, e}$ & 6 & 5 & +1 \\
\hline Ellagic acid & $190-3040$ & $y=0.5656 x+340.03$ & 0.997 & -18 to +5 & 45 & 150 & $97(4)^{\mathrm{d}, e}$ & $82(3)^{\mathrm{d}, e}$ & 6 & 4 & +5 \\
\hline Naringenin & $20-320$ & $y=25.224 x+1781$ & 0.999 & -11 to +6 & 1.5 & 5 & $98(10)^{\mathrm{d}, \mathrm{e}}$ & $103(9)^{\mathrm{d}, \mathrm{e}}$ & 12 & 15 & +4 \\
\hline
\end{tabular}

a Correlation coefficient; ${ }^{b}$ LOD: limit of detection; ${ }^{\mathrm{L}} \mathrm{LOQ}$ : limit of quantification; ${ }^{\mathrm{d}}$ recovery and precision values (intra-and inter-day) obtained analyzing five replicates at each concentration $(n=5)$; eintra-day values expressed as relative standard deviation (RSD) are given in parentheses. F1: 4-hydroxybenzoic acid $\left(10 \mu \mathrm{g} \mathrm{kg}^{-1}\right)$, vanillic acid $\left(25 \mu \mathrm{g} \mathrm{kg}^{-1}\right)$, caffeic acid $\left(14 \mu \mathrm{g} \mathrm{kg}^{-1}\right), p$-coumaric acid $\left(12 \mu \mathrm{g} \mathrm{kg}^{-1}\right)$, sinapic acid $\left(1800 \mu \mathrm{g} \mathrm{kg}^{-1}\right)$, ferulic acid $\left(1200 \mu \mathrm{g} \mathrm{kg}{ }^{-1}\right)$, ellagic acid $\left(380 \mu \mathrm{g} \mathrm{kg}^{-1}\right)$ and naringenin $\left(40 \mu \mathrm{g} \mathrm{kg}^{-1}\right) ; \mathrm{F} 2$ : 4-hydroxybenzoic acid $\left(20 \mu \mathrm{g} \mathrm{kg}^{-1}\right)$, vanillic acid $\left(50 \mu \mathrm{g} \mathrm{kg}^{-1}\right)$, caffeic acid $\left(28 \mu \mathrm{g} \mathrm{kg}{ }^{-1}\right), p$-coumaric acid $\left(24 \mu \mathrm{g} \mathrm{kg}^{-1}\right)$, sinapic acid $\left(3600 \mu \mathrm{g} \mathrm{kg}^{-1}\right)$, ferulic acid $\left(2400 \mu \mathrm{g} \mathrm{kg}^{-1}\right)$, ellagic acid $\left(760 \mu \mathrm{g} \mathrm{kg}^{-1}\right)$ and naringenin $\left(80 \mu \mathrm{gg}^{-1}\right)$.

Table 4. Phenolic composition of the different red sweet pepper cultivars

\begin{tabular}{|c|c|c|c|c|}
\hline \multirow{2}{*}{ Phenolic compound } & \multicolumn{4}{|c|}{ Phenolic composition / $\left(\mu \mathrm{g} \mathrm{kg}^{-1}\right)$} \\
\hline & "Gaston" & "Rialto" & "Pampa" & "Italian sweet" \\
\hline 4-Hydroxybenzoic acid & $21 \pm 2$ & $37 \pm 3$ & $33 \pm 8$ & $18 \pm 2$ \\
\hline Vanillic acid & $67 \pm 8$ & $45 \pm 2$ & $47 \pm 3$ & $149 \pm 9$ \\
\hline Caffeic acid & $38 \pm 5$ & $54 \pm 2$ & $56 \pm 8$ & $63 \pm 9$ \\
\hline$p$-Coumaric acid & $41 \pm 7$ & $63 \pm 1$ & $69 \pm 6$ & $14 \pm 2$ \\
\hline Sinapic acid & $2025 \pm 137$ & $181 \pm 6$ & $554 \pm 77$ & $662 \pm 48$ \\
\hline Ferulic acid & $1420 \pm 89$ & $404 \pm 26$ & $802 \pm 33$ & $2661 \pm 252$ \\
\hline Ellagic acid & $896 \pm 82$ & $2434 \pm 129$ & $1566 \pm 54$ & $1256 \pm 122$ \\
\hline Naringenin & $73 \pm 17$ & $526 \pm 100$ & $590 \pm 157$ & $968 \pm 97$ \\
\hline
\end{tabular}

Data given as mean peak area \pm standard deviation $(n=3)$.

$\left(2434 \mu \mathrm{g} \mathrm{kg}^{-1}\right)$ and "pampa" (1566 $\left.\mu \mathrm{g} \mathrm{kg}^{-1}\right)$ cultivars, and ferulic and ellagic acids (2661 and $1256 \mu \mathrm{g} \mathrm{kg}{ }^{-1}$ ) were found in higher concentrations for "Italian sweet" cultivar. The quantitative differences between the cultivars analyzed may be associated with genetic, climatic, and pre- and post-harvest conditions. ${ }^{68}$

The quantitative results for the phenolic composition from different cultivars of red sweet peppers complement the data found with respect to the phenolic composition of the $C$. anпиит L. species. Several published works, ${ }^{19,20,22,26,71}$ indicate high concentrations of flavonoids, and the present study also highlights the presence of high concentrations of phenolic acids.

\section{Conclusions}

The QuEChERS acetate method extracted the highest amounts of phenolic compounds when compared to the other QuEChERS versions evaluated (original and citrate). These results can be associated with the lower $\mathrm{pH}$ presented by this version (4.8), in which phenolic compounds are more stable. The d-SPE clean-up step was also optimized, evaluating several sorbents (PSA, C18, GCB and fluorinated) individually or in combination. Based on the chromatographic analysis and spectrophotometric analysis of the extracts obtained before and after the d-SPE clean-up step, the condition that resulted in the greatest 
removal of interferents without significant retention of the phenolic compounds was obtained with the use of $50 \mathrm{mg}$ of $\mathrm{C} 18$ combined with $7.5 \mathrm{mg}$ of GCB.

Antioxidant activity and TPC results obtained for the extracts before and after the d-SPE clean-up step showed a correlation with the chromatographic analysis, also suggesting that the clean-up step did not compromise the determination of the phenolic compounds in this study.

The method developed allowed for the determination of eight phenolic compounds in red sweet pepper at concentration levels of 2-150 $\mu \mathrm{g} \mathrm{kg}^{-1}$. Recoveries (in the range of $82-103 \%)$ and precision values $(\leq 15 \%)$ were obtained for all phenolic compounds. All of the target phenolic compounds were found in the four cultivars of the sweet red pepper evaluated, but in significantly different concentration levels. For all cultivars, sinapic, ferulic, and ellagic acids, and naringenin were found at higher concentrations.

Based on the results, the QuEChERS method was fast, easy, and efficient for the determination of phenolic compounds in red sweet peppers, being a promising method for the analysis of these compounds in fruits and vegetables.

\section{Acknowledgments}

We would like to thank Conselho Nacional de Desenvolvimento Científico e Tecnológico-Brazil (CNPq); Fundação Araucária de Apoio ao Desenvolvimento Científico e Tecnológico do Paraná; and Coordenação de Aperfeiçoamento de Pessoal de Nível Superior-Brazil (CAPES) for support and the scholarship.

\section{References}

1. Oroian, M.; Escriche, I.; Food Res. Int. 2015, 74, 10.

2. Roleira, F. M. F.; Tavares-da-Silva, E. J.; Varela, C. L.; Costa, S. C.; Silva, T.; Garrido, J.; Borges, F.; Food Chem. 2015, 183, 235.

3. Shahidi, F.; Ambigaipalan, P.; J. Funct. Foods 2015, $18,820$.

4. Manach, C.; Scalbert, A.; Morand, C.; Rémésy, C.; Jiménez, L.; Am. J. Clin. Nutr. 2004, 79, 727.

5. Silva, K. D. R. R.; Sirasa, M. S. F.; Food Chem. 2018, $238,203$.

6. Zang, S.; Tian, S.; Jiang, J.; Han, D.; Yu, X.; Wang, K.; Li, D.; Lu, D.; Yu, A.; Zhang, Z.; Food Chem. 2017, 221, 1221.

7. Cong-Cong, X.; Bing, W.; Yi-Qiong, P.; Jian-Sheng, T.; Tong, Z.; Chin. J. Nat. Med. 2017, 15, 721.

8. Singh, B.; Singh, J. P.; Kaur, A.; Singh, N.; Food Res. Int. 2017, 101,1 .

9. Catalán, U.; Barrubés, L.; Valls, R. M.; Solà, R.; Rubió, L.; Genomics, Proteomics Bioinf. 2017, 15, 236.

10. Gebhardt, C.; Theor. Appl. Genet. 2016, 129, 2281.
11. Samuels, J.; Resources 2015, 4, 277.

12. Bindler, G.; Plieske, J.; Bakaher, N.; Gunduz, I.; Ivanov, N.; van der Hoeven, R.; Ganal, H.; Donini, P.; Theor. Appl. Genet. 2011, 123, 219.

13 Ghatak, A.; Chaturvedi, P.; Paul, P.; Agrawal, G. K.; Rakwa, R.; Kim, S. T.; Weckwerth, W.; Gupta, R.; J. Proteomics 2017, $169,41$.

14. Morales-Soto, A.; Gómez-Caravaca, A. M.; García-Salas, P.; Segura-Carretero, A.; Fernández-Gutiérrez, A.; Food Res. Int. 2013, 51, 977.

15. van Zonneveld, M.; Ramirez, M.; Williams, D. E.; Petz, M.; Meckelmann, S.; Avila, T.; Bejarano, C.; Ríos, L.; Peña, K.; Jager, M.; Libreros, D.; Amaya, K.; Scheldeman, X.; PLoS One, 2015, DOI: 10.1371/journal.pone.0134663.

16. Xavier, A. A. O.; Pérez-Gálvez, A.; In Encyclopedia of Food and Health; Caballero, B.; Finglas, P. M.; Toldrá, F., eds.; Kidlington: Oxford, 2016, p. 301.

17. Embuscado, M. E.; J. Funct. Foods 2015, 18, 811.

18. Agostini-Costa, T. S.; Gomes, I. S.; Melo, L. A. M. P.; Reifschneider, F. J. B.; Ribeiro, C. S. C.; J. Food Compos. Anal. 2017, 57, 73 .

19. Sun, T.; Xu, Z.; Wu, T. C.; Janes, M.; Prinyawiwatkul, W.; No, H. K.; J. Food Sci. 2007, 72, 98.

20. Bae, H.; Jayaprakasha, G. K.; Crosby, K.; Yoo, K. S.; Leskovar, D. I.; Jifon, J.; Patil, B. S.; J. Food Compos. Anal. 2014, 33, 195.

21. Ornelas-Paz, J. J.; Martínez-Burrola, J. M.; Ruiz-Cruz, S.; Santana-Rodríguez, V.; Ibarra-Junquera, V.; Olivas, G. I.; PérezMartínez, J. D.; Food Chem. 2010, 119, 1619.

22. Zhuang, Y.; Clen, L.; Sun, L.; Cao, J.; J. Funct. Foods 2012, 4, 331.

23. Saini, R. K.; Keum, Y.-S.; J. Food Meas. Charact. 2016, 10, 685.

24. Lu, M.; Yuan, B.; Zeng, M.; Chen, J.; Food Res. Int. 2011, 44, 530.

25. Moreno-Escamilla, J. O.; de la Rosa, L. A.; López-Díaz, J. A.; Rodrigo-García, J.; Núñez-Gastélum, J. A.; Alvarez-Parrilla, E.; Food Res. Int. 2015, 76, 654.

26. Silva, C. L.; Haesen, N.; Câmara, J. S.; J. Chromatogr. A 2012 , 1260, 154.

27. Alothman, M.; Bhat, R.; Karim, A. A.; Food Chem. 2009, 115, 785 .

28. Isabelle, M.; Lee, B. L.; Lim, M. T.; Koh, W.-P.; Huang, D.; Ong, C. N.; Food Chem. 2010, 123, 77.

29. Wang, W.; Jung, J.; Tomasino, E.; Zhao, Y.; LWT - Food Sci. Technol. 2016, 72, 238.

30. Bae, H.; Jayaprakasha, G. K.; Jifon, J.; Patil, B. S.; Food Chem. 2012, 130, 758 .

31. Nicácio, A. E.; Rotta, E. M.; Boeing, J. S.; Barizão, E. O.; Kimura, E.; Visentainer, J. V.; Maldaner, L.; Food Anal. Methods 2017, 10, 2718. 
32. Rotta, E. M.; Haminiuk, C. W. I.; Maldaner, L.; Visentainer, J. V.; Int. J. Food Sci. Technol. 2017, 52, 954.

33. Luiz, A. L.; Maciel, E. V. S.; Lanças, F. M.; Sci. Chromatogr. 2015, 7, 157.

34. Anastassiades, M.; Lehotay, S.; Stajnbaher, D.; Schenck, F. J.; J. AOAC Int. 2003, 86, 412.

35. Myresiotis, C. K.; Testempasis, S.; Vryzas, Z.; Karaoglanidis, G. S.; Papadopoulou-Mourkidou, E.; Food Chem. 2015, 182, 81.

36. Delgado-Zamarreño, M. M.; Fernández-Prieto, C.; BustamanteRangel, M.; Pérez-Martín, L.; Food Chem. 2016, 192, 825.

37. Burin, V. M.; Ferreira-Lima, N. E.; Panceri, C. P.; BordignonLuiz, M. T.; Microchem. J. 2014, 114, 155.

38. Lehotay, S. J.; Maòtovská, K.; Lightfield, A. R.; J. AOAC Int. 2005, 88,615 .

39. Anastassiades, M.; Scherbaum, E.; Ta delen, B.; Štajnbaher, D. In Pesticide Chemistry: Crop Protection, Public Health, Environmental Safety; Ohkawa, H.; Miyagama, H.; Lee, P. W., eds.; Wiley-VCH: Weinheim, 2007, p. 439.

40. Ma, X.; Wu, H.; Liu, L.; Yao, Q.; Wang, S.; Zhan, R.; Xing, S.; Zhou, Y.; Sci. Hortic. 2011, 129, 102.

41. Rufino, M. S. M.; Alves, R. E.; Brito, E. S.; Morais, S. M.; Sampaio, C. G.; Pérez-Jiménez, J.; Saura-Calixto, F. D.; Metodologia Científica: Determinação da Atividade Antioxidante Total em Frutas pela Captura do Radical Livre ABTS $^{\circ+}$; EMBRAPA: Fortaleza, Brasil, 2007.

42. Ou, B.; Hampsch-Woodill, M.; Prior, R. L.; J. Agric. Food Chem. 2001, 49, 4619.

43. Singleton, V. L.; Rossi Jr., J. A.; Am. J. Enol. Vitic. 1965, 16, 58.

44. Shahidi, F.; Naczk, M.; Food Phenolics: Sources, Chemistry, Effects and Applications; Technomic: Lancaster, 1995.

45. European Commission DG-SANTE, No. SANTE/11945/2015, Guidance Document on Analytical Quality Control and Method Validation Procedures for Pesticides Residues Analysis in Food and Feed; European Commission, 2015.

46. Kaczynski, P.; Food Chem. 2017, 230, 524.

47. Ferrer, C.; Lozano, A.; Agüera, A.; Girón, A. J.; Fernández-Alba, A. R.; J. Chromatogr. A 2011, 1218, 7634.

48. Silva, F. A. S.; Azevedo, C. A. V.; Assistat ${ }^{\circledR}$, version 7.7; Universidade Federal de Campina Grande, Campina Grande, Brasil, 2016.

49. Fontana, A. R.; Bottini, R.; J. Chromatogr. A 2014, 1342, 44.
50. Tsao, R.; Nutrients 2010, 2, 1231.

51. Golge, O.; Kabak, B.; Food Chem. 2015, 176, 319.

52. Jang, J.; Rahman, M. M.; Ko, A.-Y.; El-Aty, A. M. A.; Park, J. H.; Cho, S. K.; Shim, J.-H.; Food Chem. 2014, 146, 448.

53. Jiang, Z.; Li, H.; Cao, X.; Du, P.; Shao, H.; Jin, F.; Jin, M.; Wang, J.; Food Chem. 2017, 228, 411.

54. Malhat, F. M.; Arabian J. Chem. 2017, 10, 765.

55. Nantia, E. A.; Moreno-González, D.; Manfo, F. P. T.; GámizGracia, L.; García-Campaña, A. M.; Food Chem. 2017, 216, 334.

56. Rasche, C.; Fournes, B.; Dirks, U.; Speer, K.; J. Chromatogr. A 2015, 1403, 21.

57. Wang, Z.; Cang, T.; Qi, P.; Zhao, X.; Xu, H.; Wang, X.; Zhang, H.; Wang, X.; Food Control 2015, 55, 215.

58. Cabrera, L. C.; Caldas, S. S.; Prestes, O. D.; Primel, E. G.; Zanella, R.; J. Sep. Sci. 2016, 39, 1945.

59. Kemmerich, M.; Rizzetti, T. M.; Martins, M. L.; Prestes, O. D.; Adaime, M. B.; Zanella, R.; Food Anal. Methods 2015, 8, 728.

60. Martins, M. L.; Kemmerich, M.; Prestes, O. D.; Maldaner, L.; Jardim, I. C. S. F.; Zanella, R.; J. Chromatogr. A 2017, 1415, 36.

61. Rejczak, T.; Tuzimski, T.; Open Chem. 2015, 13, 980.

62. Lehotay, S. J.; J. AOAC Int. 2007, 90, 520.

63. Hennion, M.-C.; J. Chromatogr. A 2000, 885, 74.

64. Brousmiche, D. W.; O’Gara, J. E.; Walsh, D. P.; Lee, P. J.; Iraneta, P. C.; Trammell, B. C.; Xu, Y.; Mallet, C. R.; J. Chromatogr. A 2008, 1191, 108.

65. Crini, G.; Bioresour. Technol. 2006, 97, 1061.

66. Maldaner, L.; Collins, C. H.; Jardim, I. C. S. F.; Quim. Nova 2010, 33, 1559.

67. Fernández-García, E.; Carvajal-Lérida, I.; Pérez-Gálvez, A.; Photochem. Photobiol. Sci. 2016, 15, 1204.

68. Deepa, N.; Kaur, C.; Singh, B.; Kapoor, H. C.; J. Food Compos. Anal. 2006, 19, 572.

69. Jiménez-Escrig, A.; Jiménez-Jiménez, I.; Sánchez-Moreno, C.; Saura-Calixto, F.; J. Sci. Food Agric. 2000, 80, 1686.

70. Floegel, A.; Kim, D.-O.; Chung, S.-J.; Koo, S. I.; Chun, O. K.; J. Food Compos. Anal. 2011, 24, 1043.

71. Ghasemnezhad, M.; Sherafati, M.; Payvast, G. A.; J. Funct. Foods 2011, 3, 44.
Submitted: September 13, 2018

Published online: February 5, 2019 